\title{
What Makes a Job Good or Bad? Standards of Good Work Revisited
}

Standards of good work - in economics, law, sociology and industrial psychology are rooted in ideas of protecting labour against exploitation and alienation. Certainly, these basic ideas have not lost their importance. However, organisations as sociotechnological systems have radically changed during the last decades, which entails the need for revision of the implications formulated in the 1960s and which change radically in the ongoing Corona crisis.

The 'old' answers, for example, the front against Taylorism and the bureaucratic phenomenon, prove more and more fruitless in times of the flexible organisation and subsequently flexible women and men. For example, technical progress may result not only in a reduction of workload but also in a devaluation of human capital which is bounded to persons and communities. New sourcing strategies of enterprises for example via crowd and click work platforms change the structure of relevant labour markets. Labour law may foster the unintended effect of building up a non-core workforce which is excluded from regulations which protect regular employees. The questions of how protection can be organised elsewhere, and whether monetary instruments as an unconditional minimum wage are a good remedy are still debated intensely - and become topical again in the Corona shut down of large parts of the economic system. Autonomy - the additional margin for manoeuvre intended as a resource enabling coping in models of work-related stress - may have already converted to a stressor itself at some workplaces and in some types of flexible organisations. A topical example is the experience of parents with their autonomy to work in the home office and supervise homeschooling of their children during the Corona pandemic. Changes in value orientations, which have not disappeared from the perspective of social research since decades, may newly result in altered individual demands and hence in fresh answers to the question what makes a good job. The same is true for changes in the structure of the workforce, for example concerning age, gender, generation and religious orientation.

* Prof. Dr. Dorothea Alewell: University of Hamburg, School of Business Administration, Chair for Human Resource Management, Moorweidenstraße 18, 20148 Hamburg, Germany. EMail: dorothea.alewell@uni-hamburg.de

A/Prof. Dr. Simon Fietze (corresponding author): University of Southern Denmark, Department of Entrepreneurship and Relationship Management, Alsion 2, 6400 Sønderborg, Denmark. E-Mail: simonf@sam.sdu.dk

Prof. Dr. Wenzel Matiaske: Helmut-Schmidt-University/University of the Federal Armed Forces Hamburg \& DIW Berlin, Holstenhofweg 85, 22043 Hamburg, Germany. E-Mail: matiaske@hsu-hh.de. 
The papers that have been submitted and accepted for this special issue reflect the high importance and the broad field of standards of good work: Authors tackle subjective perceptions of working conditions in mini-jobs and meaning of work, think about the more objective standards of working time organisation and work intensification, about gender stereotypes as social standards of work and the importance of altruistic work values. They ask for the relationship between working conditions and retirement age and analyse the effects of participating in processes of improving the working conditions. All the papers were written before the Corona crisis started and could thus not react to the changing circumstances and the newly emerging picture. However, we are sure that researchers in the field of standards of good work will closely monitor and scrutinize the many shifts in standards of work that happen right now - a massive increase in the use of teleworking, work in home offices and digital forms of meeting, communicating and collaborating, an increase in the importance of health aspects for labour safety, shifts in decision processes and participating structures in organisations in decisions related to the Corona pandemic, for example, restriction of freedom and participation rights and an increase in informal decision structures, erosion of relationships between workers and their organisation due to spatial and social distancing and isolation effects in home offices, to name only a few. Thus, this collection of papers and research questions is probably not the end but more of a starting point in research on good labour standards.

Two papers shed light on structural, labour law-based conditions on the labour markets and their relationship with good working conditions:

Fabian Beckmann analysis the perceived job quality in German mini-jobs. Minijobs are a special form of part-time employment where workers - and partly employers - have to pay lower social security contributions. Although labour law stipulations are in full effect for these jobs, there is anecdotical evidence that they are often practised as if in a non-regulated field - often mini jobbers get no paid vacation, no paid sick leave and no termination protection. Due to such multiple risks, mini-jobs are often considered as prime examples of low-quality jobs and are heavily criticised for their potential labour market effects, their impact on employees' social security and their bad working conditions. However, mini jobbers are a very diverse group with extremely different living situations - students supplementing what they get from their parents, married persons with small children and a spouse earning a full income, persons living from the income of multiple mini-jobs, retired persons wanting to stay active - and there has been hardly any research dealing with the subjective perception of the work situation of mini jobbers. Based on a quantitative survey, Fabian Beckmann analyses different dimensions of subjective evaluation of working conditions in mini-jobs. He concentrates on the relationship between desired and experienced work situations and global job satisfaction of mini jobbers. The analysis shows that mini-jobs are evaluated positively regarding many intrinsic, social and health-related aspects of work and that the overall job evaluation is significantly correlated to the perceived job quality. The study underlines the 
need for multidimensional and subjective approaches to job quality as well as a nuanced critique of mini-jobs which has to differentiate between the institutional regulation, the working conditions and employees' subjective perception.

Tobias Wiß, Lisa Schmidthuber and Valeria Bordone contribute to the debate about retirement standards related to retirement age. They focus on the long-lasting discussion on postponing retirement to older ages to improve the financial stability of pension systems. Prolonging employment and postponing retirement are often seen as promising solutions to adapt labour markets and pension systems to the ageing population and the low employment rates of older people. However, many discussants have asked whether the health situation of workers in sectors and jobs with hard physical working conditions and high-stress levels prevent longer working phases for specific groups of workers. So the authors turn to the status quo of this relationship between working conditions, sector and age at retirement - and empirically analyse the effect of the quality of working conditions and the sector of employment on retirement age. Their results show that autonomy - the freedom to decide how to do the work - is significantly associated with a higher age at retirement and adequate salary with a lower age at retirement among both men and women, while working in a comfortable environment, without emotional demands, and where employees experienced fair treatment is positively related to age at retirement only for men. Furthermore, the author's analysis provides evidence that quality of working conditions attributes are more important for age at retirement in the service, manufacturing and industrial sector as in the finance, trade and primary sector. A stronger focus on improving the quality of working conditions is likely to promote a higher age at retirement among both men and women.

Two papers focus on the more subjective side of good work - on the meaning of work and what gives or hampers the experiencing of meaning:

Karla Brinck, Sven Hauff and Stefan Kirchner contribute to the debate on changes in work values - important subjective criteria to evaluate what good work is. They ask whether work values have changed and whether this is a result of the changing structure of the workforce concerning age, gender and generations. Under the header 'Is there is a new meaning of work?' they analyse if, how and why the prevalence of altruistic work values has changed in Germany between 1989 and 2016. Using German data from four years between 1989 and 2016, they find small changes altruistic work values' importance has increased during the observed periods, while extrinsic work values have become less important and intrinsic work values have not changed. An increase of women and an ageing workforce contribute only marginally to a change in altruistic work values, while the shifting generational distribution, intensely discussed in public, has no effect. Overall, the effect of the changing structure of the workforce is only very small.

Friedericke Hardering writes about subjective evaluations of working conditions and about meaning, too. She starts with the question which factors impact on the sub- 
jective dimension of job quality. Although meaningful work has repeatedly been named in research as an important factor in the quality of work, as yet, there is a lack of studies investigating the subjective demands of employees for meaningful work especially in jobs evaluated as "good jobs" up to now - professional jobs in medicine and social work. Her contribution focuses on employee's subjective perception of standards of meaningful work and also asks for barriers that undermine the experience of meaningfulness at work. Economic incentives and the related bureaucratic processes seem to play a major role in forming such barriers.

Three other papers tackle gender aspects, participation in creating good working conditions and the organisation of working time and their respective impact on worker wellbeing:

Stereotypes with their normative, prescriptive parts may be interpreted as a specific form of standard, too. Sina Otten and Dorothea Alewell empirically analyze the effects of gender stereotypes on job satisfaction. More specifically, they look at the effects of individual deviation from the prescriptive aspect of gender stereotypes for male and female employees in general, and employees in leadership positions. Based on social role theory, backlash mechanisms and role incongruity theory, they expect negative repercussions of deviation from gender stereotypes on job satisfaction. Results indeed show a stable negative effect of deviation from gender stereotypes on job satisfaction, but for women only. The findings are consistent with recent studies that confirm traditional gender structures on the labour market and thus stereotype standards of work that do not correspond well with ideas of equal rights and equal opportunities as standards of good work. The recent debate on the effect of the Corona crises (with its lockdown of kindergartens and schools and home-schooling) on women and their work and career perspectives shows how topical this question is and how fast even low standards of equality on the labour market degenerate even further in the crises. Thus, their work can be read as a contribution showing that we still have bad standards of work in place in the realm of gender stereotypes.

Elisabeth Nöhammer, Michaela Drexel and Harald Gottfried Stummer ask for processes of improving working conditions. In 'Co-Creating the Good Job or the Extra Mile: Does Co-Creational Implementation of WHP Improve Working Conditions?' they start from the assumption that workplace health promotion (WHP) can be the starting point for organizational development towards becoming a healthy organization offering good jobs. Participative processes are explicit standards for designing WHP - and are often thought to be positive for the workforce. However, they may also result in employees creating 'ideal contexts' for overexertion. This paper critically examines the potentials and downsides of co-creation in the employee health context and as standard for creating a good job. The authors analyze the employee health-related co-creational processes in a faith-based hospital using multimethod organizational analysis with observational, ethnographic and interventional elements. The results indicate that the professionalism of the employees and sharing 
organizational goals can prevent co-creation of more stress and strain. Their questions and answers can easily be transferred to the field of work in a home office how do employees co-create the health context of their work at home? Do they cocreate 'the ideal contexts for overexertion' or 'the ideal contexts for good health'?

Agnieszka Piasna turns to more objective standards of good work - she analyzes the organisation of working time and the relationship between working time, schedules, flexibility arrangements between workers and employers and work intensification. She thus addresses standards of good work in terms of working time organisation and investigates how the outcomes of non-standard working hours differ by sector and occupation, as well as by incorporating detailed and comprehensive measures of working time organisation in the empirical analysis. Based on EWCS data from 2010 and 2015 for 28 EU countries, the results show that non-standard working hours and employer-driven scheduling are, on average, linked to more intense work than regular daytime hours scheduled from Monday to Friday or under worker-led flexibility arrangements. The study points to significant differences in this relationship between sectors and occupations. Among others, in low-skilled and routine occupations, and service sectors such as transport, commerce, hospitality and health, short hours of work and employer-led flexibility are associated with relatively more intense work. Even where workers have some control over their schedules, jobs in these areas are not linked to lower levels of work intensity. The findings also support the expectation of overwork in high-skilled jobs, where long hours of work and high levels of worker-led flexibility are linked to relatively more intense work. This work could inspire hypotheses on the effects of the Corona crises, home office and employee-led flexibility on work intensification - how is employee-led flexibility in home offices with or without a family different from employee-led flexibility in firms? What are the conditions under which employees manage to keep work intensity manageable - and when is overexertion more probable?

Finally, we would like to thank not only our authors and reviewers but also the German Academic Exchange Service (DAAD) who supported our seminar at IUC Dubrovnik. 